\title{
Iron Ore Reduction by Hydrogen Using a Laboratory Scale Fluidized Bed Reactor: Kinetic Investigation-Experimental Setup and Method for Determination
}

\author{
DANIEL SPREITZER and JOHANNES SCHENK
}

\begin{abstract}
The reduction kinetics of hematite iron ore fines to metallic iron by hydrogen using a laboratory fluidized bed reactor were investigated in a temperature range between $873 \mathrm{~K}$ and $1073 \mathrm{~K}$, by measuring the weight change of the sample portion during reduction. The fluidization conditions were checked regarding plausibility within the Grace diagram and the measured pressure drop across the material during experiments. The apparent activation energy of the reduction was determined against the degree of reduction and varied along an estimated twopeak curve between 11 and $55 \mathrm{~kJ} \mathrm{~mol}^{-1}$. Conventional kinetic analysis for the reduction of $\mathrm{FeO}$ to metallic iron, using typical models to describe gas-solid reactions, does not show results with high accuracy. Multistep kinetic analysis, using the Johnson-Mehl-Avrami model, shows that the initial stage of reduction from $\mathrm{Fe}_{2} \mathrm{O}_{3}$ to $\mathrm{Fe}_{3} \mathrm{O}_{4}$, and partly to $\mathrm{FeO}$, is controlled by diffusion and chemical reaction, depending on the temperature. Further reduction can be described by a combination of nucleation and chemical reaction, whereby the influence of nucleation increases with an increasing reduction temperature. The results of the kinetical analysis were linked to the shape of the curve from apparent activation energy against the degree of reduction.
\end{abstract}

https://doi.org/10.1007/s11663-019-01650-9

(C) The Author(s) 2019

\section{INTRODUCTION}

THE reduction of iron ore fines by means of fluidized bed technology has been of interest to the iron and steel industries for many years to produce direct reduced iron (DRI). ${ }^{[1]}$ In the near future, the importance of DRI will increase drastically. Overall steel production has risen about $100 \mathrm{pc}$. over the past 20 years, from 0.85 to 1.7 billion tons of crude steel. ${ }^{[2]}$ Consequently, the scrap return will also increase within the next few years, considering the fact that a typical life cycle time of steel products is 25 years. Thus, the amount of steel produced via the process route based on an electric arc furnace (EAF) will also grow in the near future. To obtain highquality steel grades, the demand for DRI will also rise as a scrap substitute in the EAF. Aside from the increasing demand, direct reduction processes have advantages over conventional steel making via blast furnace and oxygen converter, especially in terms of environmental

DANIEL SPREITZER and JOHANNES SCHENK are with the Chair of Ferrous Metallurgy, Montanuniversitaet Leoben, FranzJosef-Straße 18, 8700 Leoben, Austria. Contact e-mail: daniel.spreitzer@unileoben.ac.at

Manuscript submitted March 24, 2019.

Article published online July 24, 2019. issues. Some direct reduction processes are able to operate with high hydrogen content in the reducing gas mixture. Therefore, accompanying $\mathrm{CO}_{2}$ emissions can be reduced. The use of fluidized bed technology brings one further advantage, as fine iron ores can be used directly without a prior agglomeration step. Examples of direct reduction processes using fluidized bed technology in industrial scale are the Finmet ${ }^{[3,4]}$ and the Circored $\AA^{[5,6]}$ processes. Both are based on natural gas as an energy source, whereby in the case of Finmet ${ }^{\circledR}$, the required reducing gas mixture is produced by means of the reforming of natural gas. In contrast, the Circored ${ }^{\circledR}$ process only uses hydrogen as a reducing agent, also provided by means of the reforming of natural gas in combination with a shift reactor and a $\mathrm{CO}_{2}$ removal unit.

During the direct reduction of iron oxide with hydrogen at temperatures above $843 \mathrm{~K}$, the reduction proceeds from hematite $\mathrm{Fe}_{2} \mathrm{O}_{3}$ via magnetite $\mathrm{Fe}_{3} \mathrm{O}_{4}$ to wüstite $\mathrm{FeO}$ and finally to metallic iron $\mathrm{Fe}$. Below $843 \mathrm{~K}$, reduction occurs from magnetite directly to metallic iron, owing to wüstite not being stable below $843 \mathrm{~K}$. The reactions are shown in Eqs. [1] through [4], ${ }^{[7]}$ where y represents iron vacancies in the lattice. The values of $\Delta H$, calculated with the thermodynamic software FactSage ${ }^{\mathrm{TM}} 7.2$ (Database: FactPS, FToxide), show for each reduction step that the reduction of iron 
oxide with hydrogen is in total endotherm, so energy is required to ensure a constant temperature during reduction. In general, reduction takes place stepwise from iron with high valence to metallic iron. It is also possible that more than one reduction step takes place similarly within different areas in the particle, especially in the case of big particles, e.g. during the reduction of lump ore. ${ }^{[8]}$

$$
3 \mathrm{Fe}_{2} \mathrm{O}_{3}+\mathrm{H}_{2} \rightarrow 2 \mathrm{Fe}_{3} \mathrm{O}_{4}+\mathrm{H}_{2} \mathrm{O} \quad \Delta \mathrm{H}_{973 \mathrm{~K}}=-2.17 \mathrm{~kJ}
$$

$$
\begin{aligned}
& T<843 \mathrm{~K} \\
& \mathrm{Fe}_{3} \mathrm{O}_{4}+4 \mathrm{H}_{2} \rightarrow 3 \mathrm{Fe}+4 \mathrm{H}_{2} \mathrm{O} \quad \Delta \mathrm{H}_{773 \mathrm{~K}}=+111.28 \mathrm{~kJ}
\end{aligned}
$$

$$
\begin{aligned}
& T>843 \mathrm{~K} \\
& (1-y) \mathrm{Fe}_{3} \mathrm{O}_{4}+(1-4 y) \mathrm{H}_{2} \rightarrow 3 \mathrm{Fe}_{(1-y)} \mathrm{O}+(1-4 y) \mathrm{H}_{2} \mathrm{O} \\
& \Delta \mathrm{H}_{973 \mathrm{~K}}=+52.16 \mathrm{~kJ}
\end{aligned}
$$

$$
T>843 \mathrm{~K}
$$

$\mathrm{Fe}_{(1-y)} \mathrm{O}+\mathrm{H}_{2} \rightarrow(1-y) \mathrm{Fe}+\mathrm{H}_{2} \mathrm{O}$

$$
\Delta \mathrm{H}_{973 \mathrm{~K}}=+15.42 \mathrm{~kJ}
$$

Figure 1 shows the so-called Baur-Glässner diagram for the $\mathrm{Fe}-\mathrm{O}-\mathrm{H}_{2}$ system, with temperature on the ordinate and the gas oxidation degree $(G O D)$ on the abscissa. The $G O D$ is defined as the ratio of oxidized components over the sum of oxidized and oxidizable components in the reducing gas mixture. The thermodynamic data required for the calculation was provided by FactSage ${ }^{\mathrm{TM}}$ 7.2. The diagram shows the stability areas of different iron oxides as a function of temperature and $G O D$. It can be seen that the stability areas of metallic iron and wüstite expand with increasing temperatures. As a result, a reducing gas mixture with a similar $G O D$ has a higher reduction potential if the reduction temperature is higher. From a

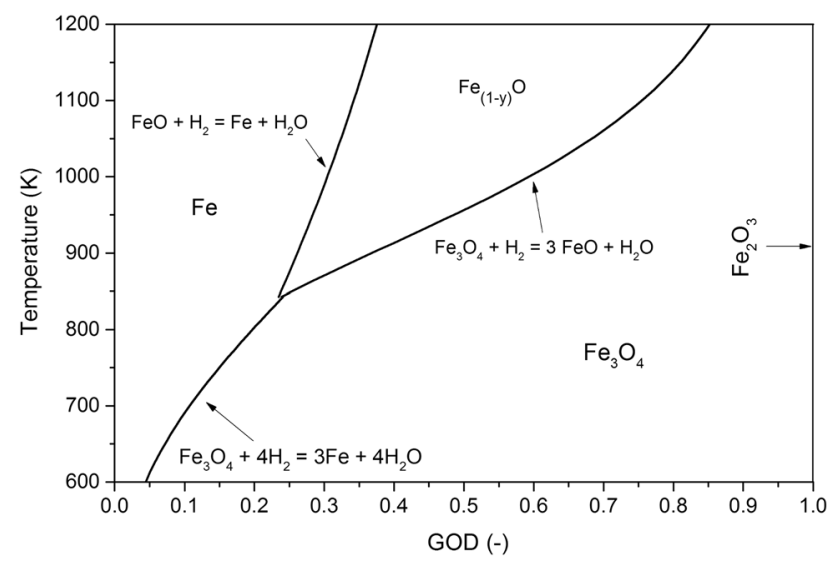

Fig. 1-Baur-Glässner diagram for the Fe-O- $\mathrm{H}_{2}$ system. thermodynamic point of view, the temperature should be as high as possible. During fluidized bed reduction, the practical temperature is limited due to sticking of the fluidized particles that can occur. This could end in a defluidization of the material. ${ }^{[9,10]}$

Investigations regarding the reduction kinetics of iron oxides using hydrogen as a reducing agent have been carried out by many authors. ${ }^{[11-19]}$ The scope of this work was to investigate the reduction kinetics of iron ore fines during fluidized bed reduction using hydrogen as a reducing agent in a suitable temperature range for an industrial application. The determination of the apparent activation energy against the degree of reduction, model-fitting analysis of experimental results as well as multistep kinetic analysis were carried out. Conclusions were drawn concerning the shape of the apparent activation energy against the degree of reduction and the results from kinetic analysis.

\section{EXPERIMENTAL PROCEDURE}

\section{A. Experimental Setup}

The schematic concept of the laboratory scale fluidized bed reactor used is shown in Figure 2. The necessary reducing gas components were stored in gas bottles and the required mixture was provided by mass flow controllers (Bronkhorst EL-Flow F201-CV/AV) in a gas mixing unit. If water vapor was required in the reducing gas mixture, the gas passed through a humidifier (Bronkhorst Evaporator W-303A-333-K), where the $\mathrm{H}_{2} \mathrm{O}$ was added to the mixture. The preheating of the reducing gas to reduction temperature took place while passed through the supply pipe inside a 3-stage electrical heating shell, where the reactor itself was also located during the experiment. The reducing gas entered the reactor from the bottom, passed the grid and fluidized the material. To remove accompanying dust from the gas, an internal cyclone and a dust filter unit were installed before the off-gas left to the atmosphere. The pressure inside the reactor was controlled by a pressure regulator (Masoneilan 28-23131), located in the off-gas duct. To evaluate the fluidization behavior, differential pressure measurements (Kobold Smart pressure transmitter) were carried out under the grid and above the material. To control the temperature of the reducing gas mixture and the sample portion, thermocouples (type N) were installed below the grid and inside the sample portion. The weight loss sustained during the reduction was measured via a scale (Mettler Toledo XP64000L), which showed the weight of the whole reactor including the material. To minimize iron ore losses, the upper part of the reactor was designed in a conical shape to reduce the superficial gas velocity. The geometrical shape and the operating conditions of the fluidized bed reactor can be summarized as follows: $68 \mathrm{~mm}$ bed diameter of reactor with conical shape in the gas outlet area; perforated grid with 33 orifices ( $1 \mathrm{~mm}$ in diameter); temperature up to $1373 \mathrm{~K}$; absolute pressure up to 1.4 bar; sample mass up to $650 \mathrm{~g}$ and the reducing gas contained $\mathrm{H}_{2}, \mathrm{~N}_{2}$ and $\mathrm{H}_{2} \mathrm{O}\left(\mathrm{CO}, \mathrm{CO}_{2}\right.$ and $\mathrm{CH}_{4}$ were also possible). 


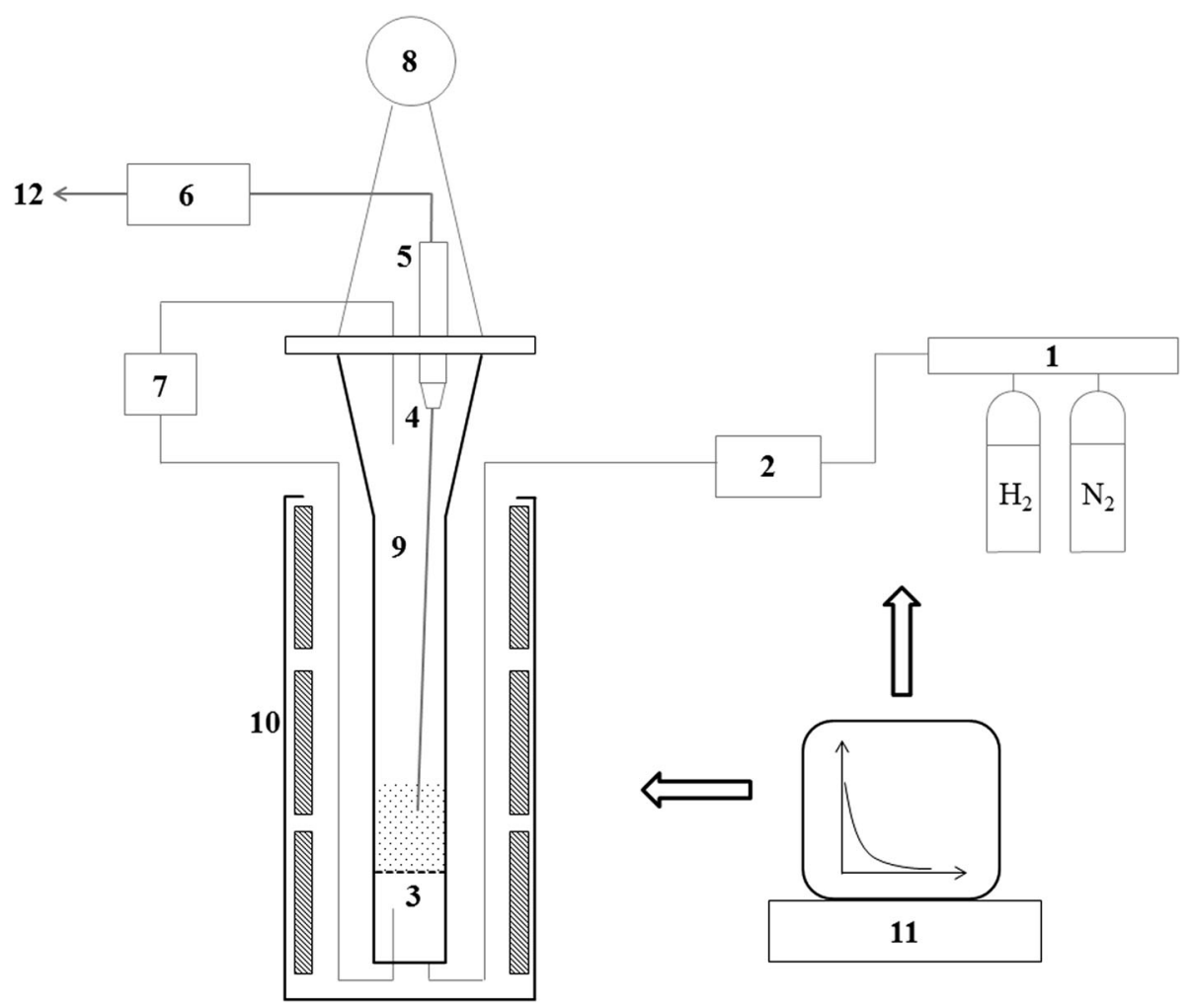

Fig. 2-Experimental setup laboratory fluidized bed reactor: 1-gas mixing unit; 2-humidifier; 3-grid; 4-internal cyclone; 5-filter unit; 6-pressure regulator; 7-differential pressure measurement; 8-weighing device; 9-reactor; 10-3-stage electrical heating shell; 11-process control; 12 - off-gas to atmosphere.

Before the experiment, the iron ore sample was placed into the reactor and purged with $\mathrm{N}_{2}$ to remove oxygen from the system. The heating period to the desired reduction temperature took place under constant $\mathrm{N}_{2}$ flow. After that, a temperature-equilibrium period of 10 minutes was chosen in order to reach a stable weight signal and a constant temperature. Then, $\mathrm{N}_{2}$ was replaced by the defined reducing gas mixture and the reduction procedure started. The change in the sample weight and the differential pressure through the grid and sample portion were measured during the experiment to evaluate the reduction and fluidization behavior. After the reduction period, the reducing gas mixture was substituted by $\mathrm{N}_{2}$ again, and the sample was cooled down to ambient temperature before discharging.

\section{B. Experimental Conditions}

To evaluate the kinetics of the reduction of hematite iron ore by hydrogen, reduction experiments were carried out at different temperatures. The chemical analysis of the iron ore as well as the specific surface area and the general test parameters are shown in Table I. A 400-g sample portion with a grain size between 250 and $500 \mu \mathrm{m}$ was used for each test. The reducing gas mixture consisted of $65 \mathrm{pc}$. $\mathrm{H}_{2}$ and $35 \mathrm{pc}$. $\mathrm{N}_{2}$, by volume, with a constant flow rate of $25.9 \mathrm{Nl} \mathrm{min}{ }^{-1}$. $\mathrm{N}_{2}$ was added to the gas mixture to support the fluidization of the particles. A constant molar flow at different temperatures ends in different superficial gas velocities inside the reactor. As a suitable temperature
Table I. Chemical Analysis of Iron Ore and Process Conditions

\begin{tabular}{|c|c|c|c|}
\hline \multicolumn{2}{|c|}{ Analysis Iron Ore } & \multicolumn{2}{|c|}{ Test Parameters } \\
\hline $\mathrm{Fe}_{\text {tot }}^{\mathrm{a}}$ & $63.6 \mathrm{wt}$ pc. & input iron ore & $400 \mathrm{~g}$ \\
\hline $\mathrm{FeO}$ & 0.58 wt pc. & particle size & 250 to $500 \mu \mathrm{m}$ \\
\hline $\mathrm{SiO}_{2}$ & 3.48 wt pc. & gas mixture & $\mathrm{H}_{2} / \mathrm{N}_{2} 65 / 35$ vol pc. \\
\hline $\mathrm{Al}_{2} \mathrm{O}_{3}$ & $2.07 \mathrm{wt}$ pc. & flow rate & $25.9 \mathrm{Nl} \mathrm{min}-1$ \\
\hline $\mathrm{LOI}^{\mathrm{b}}$ & $2.2 \mathrm{pc}$. & temperature & 873 to $1073 \mathrm{~K}$ \\
\hline $\mathrm{BET}^{\mathrm{c}}$ & $11.83 \mathrm{~m}^{2} \mathrm{~g}^{-1}$ & pressure & 1.1 bar abs. \\
\hline
\end{tabular}

range for fluidized bed reduction, $873 \mathrm{~K}$ to $1073 \mathrm{~K}$ was chosen, whereby for each $50 \mathrm{~K}$, one reduction experiment was performed. At $873 \mathrm{~K}$, a flow rate of $25.9 \mathrm{Nl} \mathrm{min}-1$ represents a superficial gas velocity of $0.35 \mathrm{~m} \mathrm{~s}^{-1}$, while at $1073 \mathrm{~K}$, it is $0.43 \mathrm{~m} \mathrm{~s}^{-}$. An absolute pressure of $1.1 \mathrm{bar}$ was provided to the sample portion during reduction.

The measured weight change can be directly converted into the degree of reduction and metallization using the chemical analysis of the iron ore. The degree of reduction, $R D$, is defined as shown in Eq. [5] and the metallization, Met, as presented in Eq. [6]:

$$
R D[\mathrm{pct}]=\left(1-\frac{O}{1.5 \cdot \mathrm{Fe}_{\mathrm{tot}}}\right) \cdot 100
$$


Table II. Calculation Parameters of the Grace Diagram

\begin{tabular}{llll}
\hline Density Fluid 973 K & $\rho_{\mathrm{F}}$ & 0.076 & $\mathrm{~kg} \mathrm{~m}^{-3}$ \\
Density Solids & $\rho_{\mathrm{S}}$ & 3,500 & $\mathrm{~kg} \mathrm{~m}^{-3}$ \\
Kinematic Viscosity Fluid 973 K & $\eta$ & $3.71 \mathrm{E}-5$ & $\mathrm{~Pa} \mathrm{~s}$ \\
Minimum Fluidization Porosity & $\varepsilon_{\mathrm{mf}}$ & 0.39 & - \\
Sphericity Solids & $\varphi_{\mathrm{s}}$ & 0.86 & - \\
\hline
\end{tabular}

$$
\operatorname{Met}[\mathrm{pct}]=\frac{\mathrm{Fe}_{\mathrm{met}}}{\mathrm{Fe}_{\mathrm{tot}}} \cdot 100
$$

where $\mathrm{Fe}_{\text {tot }}$ represents the total iron amount of the iron ore sample and $O$ the amount of oxygen bonded on iron in mol.

To evaluate the fluidization conditions during the reduction experiments, a calculation of the Grace diagram was done. The Grace diagram shows the dimensionless gas velocity against dimensionless particle diameter. The calculation values used for the experimental conditions at $973 \mathrm{~K}$ are summarized in Table II. The density and viscosity of the fluid were calculated according to the proposed procedure from the VDI Heat Atlas. ${ }^{[20]}$ The value for sphericity of the solids was determined experimentally by measuring the minimum fluidization velocity in comparison with the results from the calculation using the Ergun equation.

For the calculation of the Grace diagram, Eqs. [7] through [11] were used. ${ }^{[21-23]}$ Equation [7] shows the Ergun equation for the determination of the minimum fluidization velocity. Equation [8] allows the calculation of the terminal velocity, whereby $c_{D}$ represents the Drag coefficient, which can be calculated using Eq. [9]. $\mathrm{Re}_{\mathrm{p}}$ represents the particle Reynolds number. The transformation of gas velocity and particle diameter into dimensionless numbers, as required for the Grace diagram, can be done using Eqs. [10] and [11]. The usage of dimensionless particle diameter and gas velocity is helpful because each of them includes only $d_{p}$ or $u$ and properties which are constant for a given fluid-solid system. Therefore, different process conditions can be shown easily.

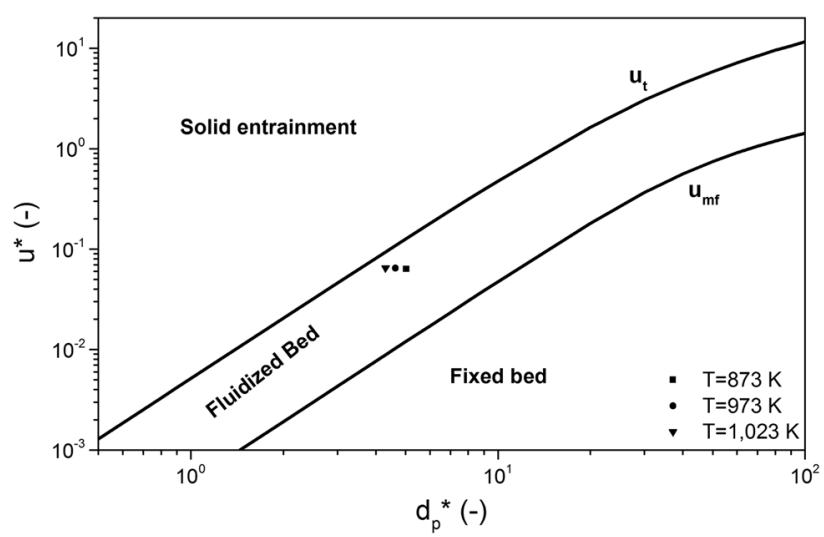

Fig. 3- Grace diagram including experimental conditions for the reduction tests.

$$
\begin{gathered}
u_{t}=\left(\frac{4 d_{p}\left(\rho_{s}-\rho_{g}\right) g}{3 \rho_{g} C_{D}}\right)^{0.5} \\
C_{D}=\frac{24}{\operatorname{Re}_{p}}\left[1+\left(8.1716 e^{-4.0655 \Phi_{s}}\right) \operatorname{Re}_{p}^{0.0964+0.5565 \Phi_{s}}\right] \\
+\frac{73.9\left(e^{-5.0748 \Phi_{s}}\right) \operatorname{Re}_{p}}{\operatorname{Re}_{p}+5.378 e^{6.2122 \Phi_{s}}} \\
u^{*}=u\left(\frac{\rho_{F}^{2}}{\eta\left(\rho_{s}-\rho_{F}\right) g}\right)^{1 / 3} \\
d_{p}^{*}=d_{p}\left(\frac{\rho_{F}\left(\rho_{S}-\rho_{F}\right) g}{\eta^{2}}\right)^{1 / 3}
\end{gathered}
$$

Figure 3 shows the resulting Grace diagram, including the experimental conditions for $873 \mathrm{~K}, 973 \mathrm{~K}$ and $1073 \mathrm{~K}$ reduction temperatures. As shown, the experimental conditions with constant gas flow rate are always in the area of the fluidized bed. Gas velocities below the line of minimum fluidization velocity $u_{\mathrm{mf}}$ will end in a fixed bed without particle movement, while gas velocities above the line of the terminal velocity $u_{t}$ will end in an entrainment of solid particles.

$$
u_{\mathrm{mf}}=\frac{-\frac{150\left(1-\varepsilon_{\mathrm{mf}}\right)}{\varepsilon_{\mathrm{mf}}^{3} \Phi_{s}^{2}} \frac{d_{P} \rho_{F}}{\eta}+\sqrt{\left(\frac{150\left(1-\varepsilon_{\mathrm{mf}}\right)}{\varepsilon_{\mathrm{mf}}^{3} \Phi_{s}^{2}} \frac{d_{P} \rho_{F}}{\eta}\right)^{2}-4 * \frac{1.75}{\varepsilon_{\mathrm{mf}}^{3} \Phi_{s}}\left(\frac{d_{P} \rho_{F}}{\eta}\right)^{2} *\left(-\frac{d_{P}^{3} \rho_{g}\left(\rho_{s}-\rho_{F}\right) g}{\eta^{2}}\right)}}{\frac{3.5}{\varepsilon_{\mathrm{mf}}^{3} \Phi_{s}}\left(\frac{d_{P} \rho_{g}}{\eta}\right)^{2}}
$$




\section{RESULTS AND DISCUSSION}

\section{A. Experimental Results}

During every experiment, the weight loss, temperature of the sample portion and pressure drop across the grid and bed were measured. Figure 4 summarizes the results for a reduction temperature of $973 \mathrm{~K}$. Figure 4(a) shows the change in sample weight and the sample temperature against reduction time. It can be seen that a residence time of 4250 seconds is required to reach a constant

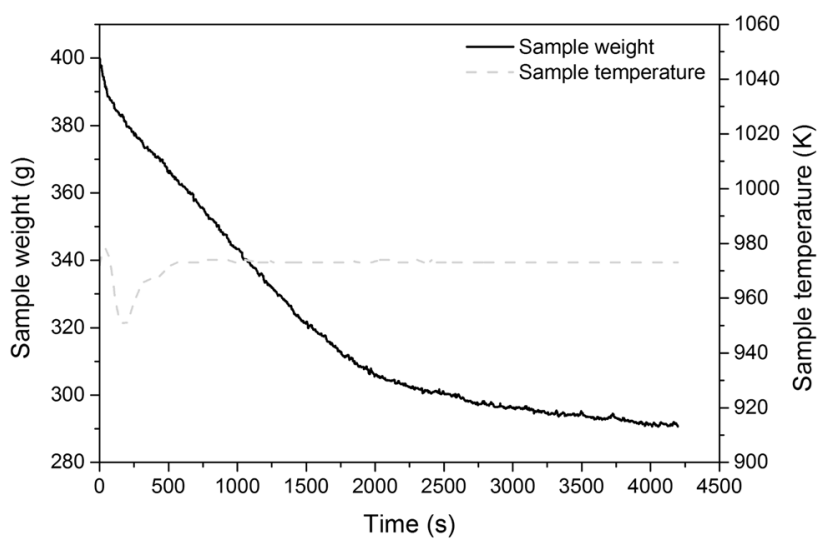

(a)

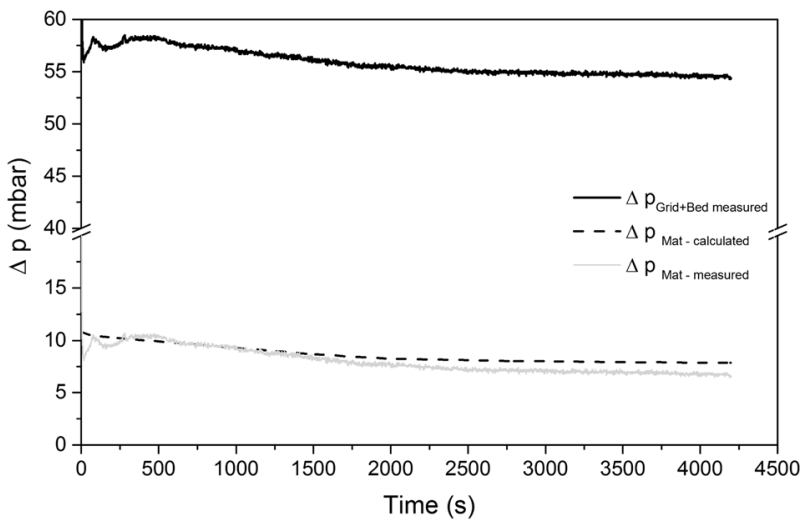

(b)

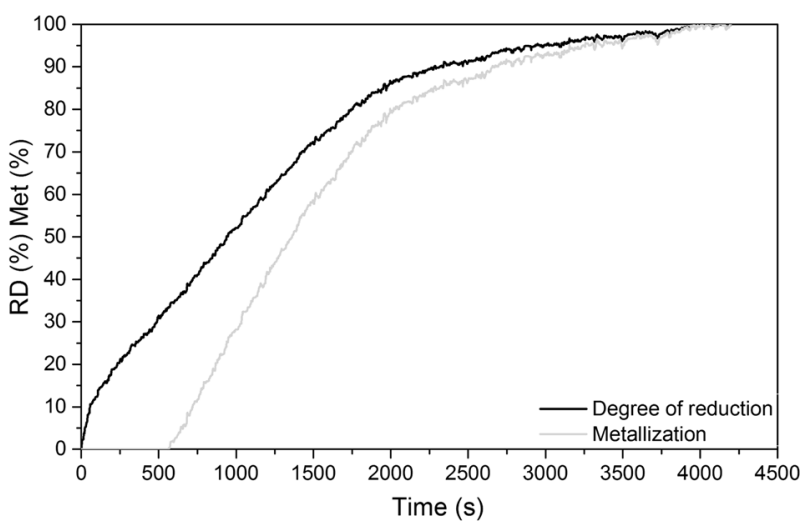

(c)

Fig. 4-Experimental results for $973 \mathrm{~K}$ reduction temperature; (a) weight loss and temperature against time; $(b)$ pressure drop grid and material against time; $(c)$ degree of reduction and metallization against time. weight signal that indicates a complete reduction. After a short increase in the sample temperature at the beginning (slightly exothermic behavior of reduction reaction from $\mathrm{Fe}_{2} \mathrm{O}_{3}$ to $\mathrm{Fe}_{3} \mathrm{O}_{4}$ at $973 \mathrm{~K}$ ), a temperature drop of $20 \mathrm{~K}$ during reduction from magnetite to wüstite occurred due to the strong endothermic reaction behavior. It took some minutes to reach the required reduction temperature again, which may influence further kinetical investigations of the experiments. This happened during all experiments to the same extent due to the thermal inertia of the system. Figure 4(b) shows the measured pressure drop that occurred during the passing of the grid and sample portion (black line). The gray line only represents the differential pressure for the material without the grid. This line should be equal to the dotted black line, which represents the theoretical differential pressure drop over the material, calculated from sample mass at the beginning and the weight loss sustained during reduction. As shown, there are small deviations between these two lines. Two reasons are responsible for these deviations. One, the entrained material was not considered in the theoretical calculation. The amount of entrained material was $21.4 \mathrm{~g}$ during the whole reduction experiment, which represents a pressure drop of $0.6 \mathrm{mbar}$; two, there were still some inaccuracies while measuring the differential pressure across the grid under reduction conditions before the experiment itself. Figure 4(c) shows the degree of reduction and metallization against reduction time, calculated from the weight loss and chemical analysis of the iron ore shown in Table I. The progress of reduction can be divided into three stages; a fast reduction at the beginning from hematite to magnetite, followed by a nearly constant reduction rate up to $85 \mathrm{pc}$. degree of reduction. In the final stage, the reduction rate slowed down until it reached a complete reduction to metallic iron.

Figure 5 shows the comparison of the reduction progress at different temperatures. All other process parameters are the same. As shown, a higher temperature increases the reduction rate, especially at the intermediate and final stages of reduction. In terms of kinetics, a higher temperature is beneficial due to the limiting effects regarding diffusion, nucleation and

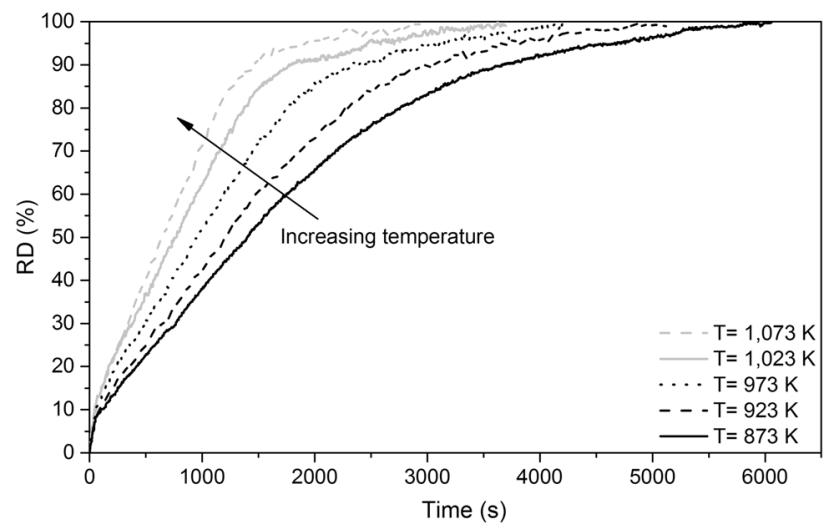

Fig. 5-Comparison of the progress of reduction at different temperatures. 
growth of nuclei, and chemical reaction decreases. In the case of reduction with hydrogen, a higher temperature is also preferable from a thermodynamic point of view due to the expanding stability area of iron with increasing temperatures. Figure 6 shows the comparison between experimental results and the thermodynamic equilibrium for reduction temperatures 873 and $1073 \mathrm{~K}$. The thermodynamic equilibriums were calculated using FactSage $^{\text {TM }} 7.2$ (Databases: FactPS, FT Oxide). Therefore, the hydrogen input flow rate and the sample amount of the experiments were used, which are similar for both experiments, given by $16.9 \mathrm{Nl} \mathrm{m^{-1 }}$ and $400 \mathrm{~g}$, respectively. Depending on the reduction temperature (for the calculation a constant reduction temperature was assumed during the whole experiment), different possible gas utilizations could be achieved, corresponding to the Baur-Glässner diagram shown in Figure 1. With the given process parameters and sample amount, the amount of oxygen which could be removed from the iron ore can be calculated and converted into a curve of reduction degree against time. That is why it takes less time for complete reduction at higher temperatures due to the expansion of $\mathrm{Fe}$ and $\mathrm{FeO}$ stability areas with increasing temperature. As exhibited, the influence regarding kinetics decreases drastically with an increasing temperature. The reduction at $1073 \mathrm{~K}$ proceeds near the thermodynamic equilibrium, up to $85 \mathrm{pc}$. degree of reduction. Afterwards, the reduction rate decreases. For $873 \mathrm{~K}$, there is still a higher deviation between the experimental results and the thermodynamic equilibrium. Kinetic analysis should give an explanation regarding this different behavior.

\section{B. Determination of Apparent Activation Energy Using the Model-Free Method}

The rate constant and apparent activation energy of isothermal gas-solid reactions can be defined as follows ${ }^{[24]}$ :

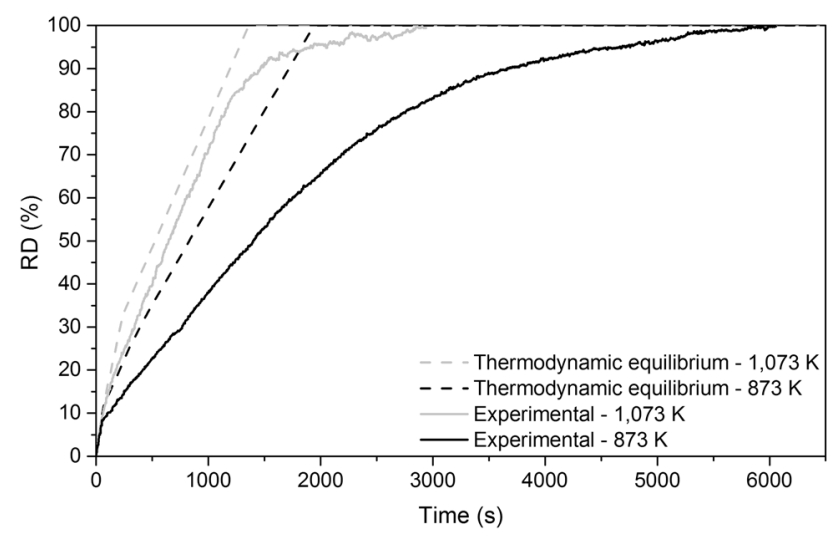

Fig. 6-Comparison of the experimental results with thermodynamic equilibrium.

$$
\begin{gathered}
\frac{\mathrm{d} x}{\mathrm{~d} t}=k(T) \times f(x) \\
g(x)=\int_{0}^{x} \frac{\mathrm{d} x}{f(x)}=k(T) \times t
\end{gathered}
$$

where $k(T)$ represents the temperature-dependent Arrhenius rate constant and $f(x)$ denotes a mathematical function, which depends on the kinetic model used and remains constant at a certain temperature and gaseous concentration. Eq. [12] can be integrated to acquire the integral expression $g(x)$. Using experimental data for conversion against time in Eq. [13], the rate-limiting step can be evaluated via the model-fitting method. The relationship among $k(T)$, temperature $T$ and apparent activation energy $E_{a}$ is given by the Arrhenius equation, Eq. [14]. $A$ denotes the pre-exponential factor, and $R$ represents the gas constant. To determine the apparent activation energy, a combination of Eqs. [12] and [14] is required, which results in Eq. [15]. ${ }^{[25]}$

$$
\begin{gathered}
k(T)=A * e^{-\frac{E_{a}}{R * T}} \\
\frac{\mathrm{d} x}{\mathrm{~d} t}=A * e^{-\frac{E_{a}}{R * T}} * f(x) \\
\ln \left(\frac{\mathrm{d} x}{\mathrm{~d} t}\right)=-\frac{E_{a}}{R * T}+\ln (A)+\ln [f(x)]
\end{gathered}
$$

The logarithmic form of Eqs. [15] is shown in [16], to evaluate the apparent activation energy via linear regression. Figure 7 shows the reduction rates for different temperatures from 5 to $95 \mathrm{pc}$. degree of reduction, where $\mathrm{d} x / \mathrm{d} t$ also represents $\mathrm{d} R D / \mathrm{d} t$. It can be seen that the reduction rate increases slightly between 30 and 50 pc. degree of reduction at high temperatures. This indicates a limitation by nucleation and growth of nuclei during the initial formation of metallic iron. For the evaluation of the apparent activation

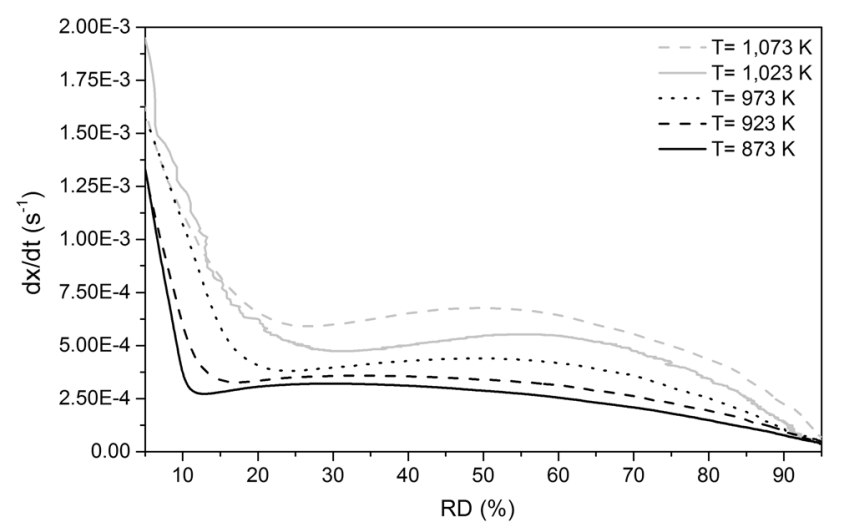

Fig. 7-Reduction rate against degree of reduction. 


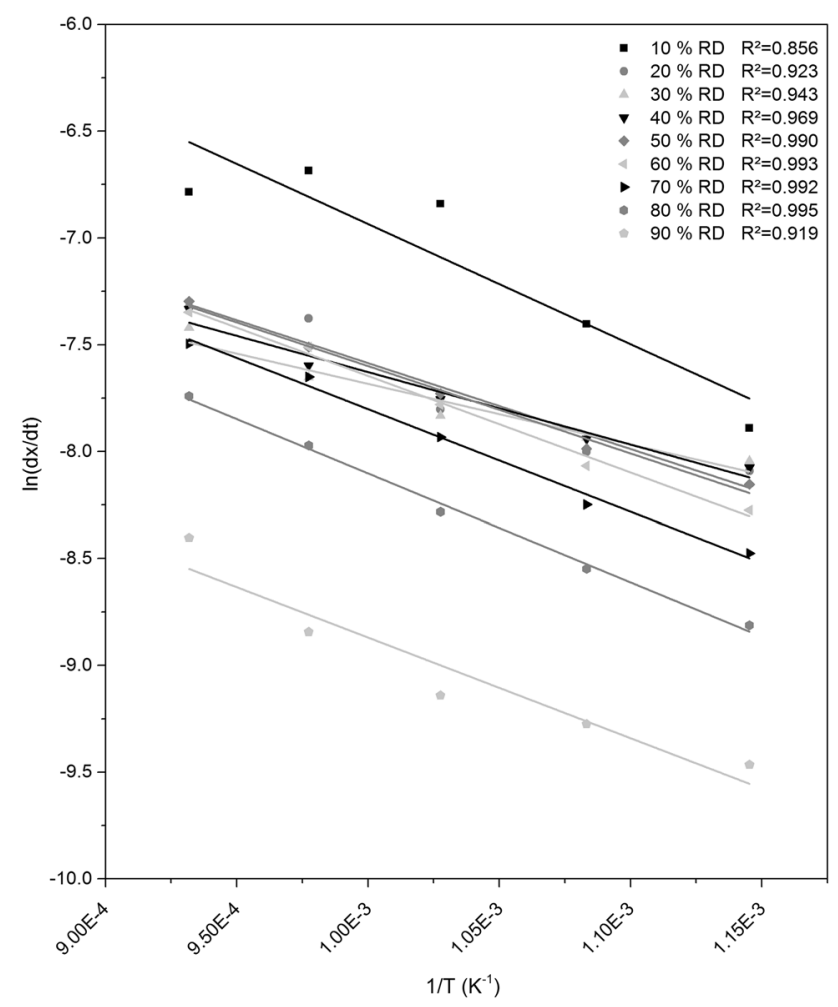

Fig. 8-Arrhenius plot for selected conversions of experimental results.

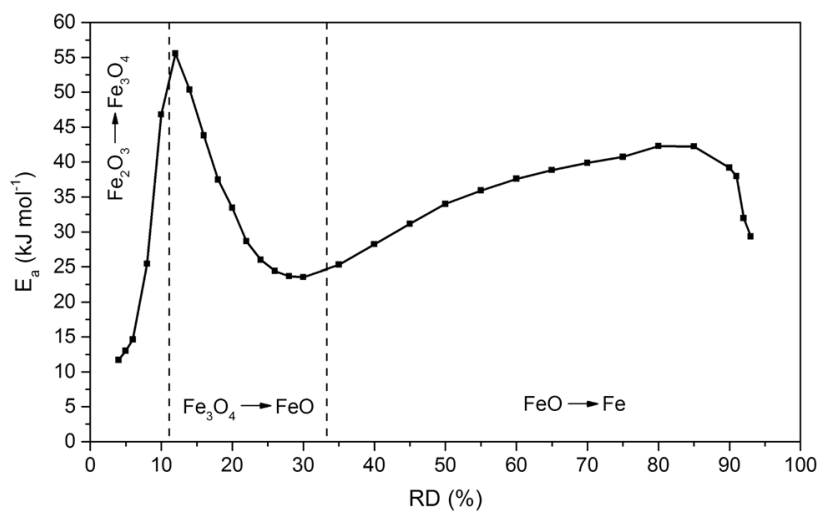

Fig. 9-Curve of apparent activation energy against degree of reduction.

energy against the degree of reduction, the mathematical function $f(x)$ was set to 1 , which ends in a modelfree fitting. The corresponding Arrhenius plot is shown in Figure 8 for different degrees of reduction. The apparent activation energies can be determined using the slope of the regression lines. As exhibited, the slope is not similar for all degrees of reduction. The resulting two-peak-shaped curve of the apparent activation energy against the degree of reduction is shown in Figure 9. The vertical lines at 11.1 and $33.3 \mathrm{pc}$. degree of reduction represent a complete reduction to $\mathrm{Fe}_{3} \mathrm{O}_{4}$ and $\mathrm{FeO}$, respectively. The apparent activation energy rises to $55 \mathrm{~kJ} \mathrm{~mol}^{-1}$ until a degree of reduction of $12 \mathrm{pc}$. is reached, which represents nearly the complete reduction from $\mathrm{Fe}_{2} \mathrm{O}_{3}$ to $\mathrm{Fe}_{3} \mathrm{O}_{4}$. Afterwards, it decreases to $23 \mathrm{~kJ} \mathrm{~mol}^{-1}$ until a degree of reduction of 30 pc. is achieved, which indicates a nearly complete reduction to $\mathrm{FeO}$. The second peak is not as drastic as the first one and goes up to $42 \mathrm{~kJ} \mathrm{~mol}^{-1}$, reaching the top at a degree of reduction of $85 \mathrm{pc}$. Two peaks can be observed during the reduction procedure, indicating that the apparent activation energy is not constant. Similar shaped curves of the apparent activation energy for the reduction of hematite fines with $\mathrm{CO}$ in a micro-fluidized bed reaction analyzer were determined by Chen et al. ${ }^{[26]} \mathrm{A}$ change in apparent activation energy always occurs when the change in reduction rate at different temperatures takes place in a different way. For that reason, a change in rate-limiting steps at different reduction temperatures must occur. The apparent activation energy increases with further progress of reduction from $\mathrm{FeO}$ to $\mathrm{Fe}$, which signifies that the overall reduction may be controlled by another mechanism, e.g. chemical reaction and nucleation. It seems that the reduction from $\mathrm{Fe}_{2} \mathrm{O}_{3} \rightarrow$ $\mathrm{Fe}_{3} \mathrm{O}_{4}$ has the highest apparent activation energy, followed by $\mathrm{FeO} \rightarrow \mathrm{Fe}$ and $\mathrm{Fe}_{3} \mathrm{O}_{4} \rightarrow \mathrm{FeO}$ reductions. Similar trends have been reported by Munteanu et al. ${ }^{[27]}$ and Shimokawabe et al. ${ }^{[28]}$

\section{INVESTIGATIONS OF KINETICS}

The following sections detail the kinetical investigations carried out regarding the experimental data. To achieve accurate results, conventional kinetic analysis was done using only experimental data from 33 to 100 pc. degree of reduction, so only the reduction from $\mathrm{FeO}$ to $\mathrm{Fe}$ was taken into account. For the evaluation of the total reduction processes from $\mathrm{Fe}_{2} \mathrm{O}_{3}$ to $\mathrm{Fe}$, multistep kinetic analysis was performed.

\section{A. Conventional Kinetic Analysis for the Reduction of $\mathrm{FeO}$ to $\mathrm{Fe}$-Approach $\mathrm{I}$}

To acquire knowledge regarding the rate-limiting mechanism, the model-fitting method was employed. Experimental data from 33 to 100 pc. degree of reduction, representing the reduction from $\mathrm{FeO}$ to $\mathrm{Fe}$, was used. This assumes that the reduction to $\mathrm{FeO}$ was complete at $33 \mathrm{pc}$. degree of reduction. The models employed to describe gas-solid reactions are listed in Table III. They can be divided into four groups, including phase-boundary-controlled models, diffusion models, reaction-order models and nucleation models.

Figure 10 shows the fitting results of experimental data at $973 \mathrm{~K}$ reduction temperature using the models shown in Table III, whereby only the rate-limiting step for the reduction of $\mathrm{FeO}$ to $\mathrm{Fe}$ was determined. Plotting the integral expression $g(x)$ against reduction time should give a straight line, with a coefficient of determination $R^{2}$ close to one. The results indicate that this 
Table III. Mathematical Models to Describe Gas-Solid Reactions ${ }^{[29,30]}$

\begin{tabular}{|c|c|c|c|}
\hline Model & & $f(x)$ & $g(x)$ \\
\hline \multicolumn{4}{|c|}{ Phase-boundary-controlled } \\
\hline PBC1 & infinite slab & 1 & $x$ \\
\hline $\mathrm{PBC} 2$ & contracting cylinder & $2(1-x)^{1 / 2}$ & $1-(1-x)^{1 / 2}$ \\
\hline PBC3 & contracting sphere & $3(1-x)^{1 / 3}$ & $1-(1-x)^{1 / 3}$ \\
\hline \multicolumn{4}{|c|}{ Diffusion models } \\
\hline D1 & one-dimensional & $1 /(2 x)$ & $x^{2}$ \\
\hline D2 & two-dimensional & $(-\ln (1-x))^{-1}$ & $x+(1-x) \ln (1-x)$ \\
\hline D3 & three-dimensional Jander & $3 / 2(1-x)^{2 / 3}\left(1-(1-x)^{1 / 3}\right)^{-1}$ & $\left.(1-1-x)^{1 / 3}\right)^{2}$ \\
\hline D4 & three-dimensional ginstling & $3 / 2\left((1-x)^{-1 / 3}-1\right)^{-1}$ & $(1-2 / 3 x)-(1-x)^{2 / 3}$ \\
\hline \multicolumn{4}{|c|}{ Reaction-order models } \\
\hline ROM1 & first order & $1-x$ & $-\ln (1-x)$ \\
\hline ROM2 & 1.5 order & $(1-x)^{3 / 2}$ & $2\left((1-x)^{-1 / 2}-1\right)$ \\
\hline ROM3 & second order & $(1-x)^{2}$ & $(1-x)^{-1}-1$ \\
\hline \multicolumn{4}{|c|}{ Nucleation models } \\
\hline NM1 & $n=1.5$ & $2 / 3(1-x)(-\ln (1-x))^{1 / 3}$ & $(-\ln (1-x))^{2 / 3}$ \\
\hline NM2 & $n=2$ & $2(1-x)(-\ln (1-x))^{1 / 2}$ & $(-\ln (1-x))^{1 / 2}$ \\
\hline NM3 & $n=3$ & $3(1-x)(-\ln (1-x))^{2 / 3}$ & $(-\ln (1-x))^{1 / 3}$ \\
\hline NM4 & $n=4$ & $4(1-x)(-\ln (1-x))^{3 / 4}$ & $(-\ln (1-x))^{1 / 4}$ \\
\hline
\end{tabular}

stage of reduction may follow the diffusion model D4, the first-order reaction model ROM1, and the nucleation model NM1 with a coefficient of determination $R^{2} \geq 0.98$ as the three best-fitting models.

Table IV shows the calculated values of the coefficient of determination for each model at different reduction temperatures. The three best-fitting models are marked bold. The results show that no general trend can be observed. The diffusion model D4 fits well at all reduction temperatures, whereby at lower reduction temperature, the phase-boundary model PBC3 becomes relevant. The reaction-order model ROM1 only fits well at higher reduction temperatures, while the nucleation model NM1 fits well in a temperature range between $923 \mathrm{~K}$ and $973 \mathrm{~K}$. In general, it is difficult to evaluate model-fitting results using only the coefficient of determination, because other models also have quite a high value of $R^{2}$. Thus, it is not possible to define one rate-limiting step from the results. This type of model-fitting procedure can only give an idea about the rate-limiting step; an accurate statement is not possible.

\section{B. Conventional Kinetics Analysis for the Reduction of $\mathrm{FeO}$ to $\mathrm{Fe}$-Approach 2}

Another approach to defining the rate-limiting step is the fitting of selected models from Table III to experimental results by variation of the rate constant to minimize the root mean square deviation (RMSD). In this case, it can be seen in which part of the reduction the utilized model matches the experimental results. The $R M S D$ is defined as follows ${ }^{[11]}$ :

$$
\operatorname{RMSD}=\sqrt{\frac{\sum\left(x_{\mathrm{calc}}-x_{\mathrm{exp}}\right)}{n-1}}
$$

$R M S D$ was used to compare the calculation results with the experimental data, where $x_{\text {calc }}$ represents the calculated values, $x_{\exp }$ the experimental ones, and $n$ the number of data sets. According to the results from conventional kinetic analysis Approach 1, the models PBC3, D3, ROM1, and NM1 were selected. Figure 11 shows the fitting curves of the different models for the reduction of $\mathrm{FeO}$ to $\mathrm{Fe}$ at $973 \mathrm{~K}$ reduction temperature; therein, $x$ represents the experimental data. It can be seen that different models fit quite well to the experimental data at different stages of reduction, but there is still no model available that is suitable during the whole reduction process. Consequently, it seems that different rate-limiting steps act at different stages of reduction. At the beginning, the PBC3 model fits best to the experimental results, while at the final stage, the ROM1 model is the best one.

Table V summarizes the resulting values for the fitted rate constants and the corresponding RMSD at different reduction temperatures. The values for RMSD show that the models PBC3 and ROM1 fit best (highlighted in bold) at a reduction temperature ranging from $873 \mathrm{~K}$ to $1023 \mathrm{~K}$. At $1073 \mathrm{~K}$, however, the NM1 model of nucleation is the most suitable, which indicates that nucleation appears more important with increasing temperatures. This kind of analysis also assumes that the reduction to $\mathrm{FeO}$ is finished at $33 \mathrm{pc}$. degree of reduction.

\section{Comparison of Arrhenius Activation Energy Values}

Values of Arrhenius activation energy are defined for the best-fitting models from Approach 1, as well as for all models used from Approach 2. From the first approach, $k$ values were determined from the slopes of 


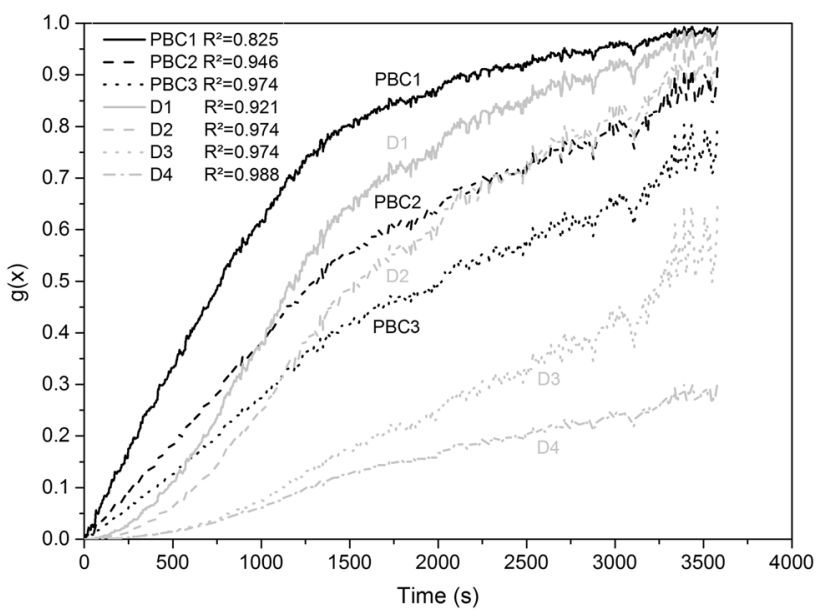

(a)

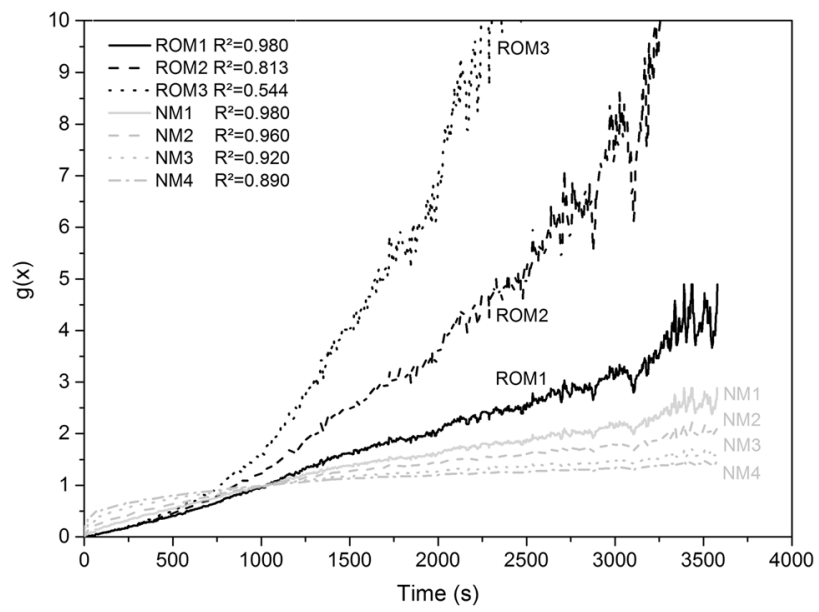

(b)

Fig. 10-Model-fitting analysis of experimental data for reduction of $\mathrm{FeO}$ to $\mathrm{Fe}$ at $973 \mathrm{~K}$ using reaction models from Table III. (a) PBC and D models. $(b)$ ROM and NM models. $R^{2}$ indicates the coefficient of determination.

Table IV. Model-Fitting Analysis of Experimental Data for Reduction of FeO to Fe Showing Coefficient of Determination at Different Temperatures-Approach1

\begin{tabular}{lccccc}
\hline Model & $873 \mathrm{~K}$ & $923 \mathrm{~K}$ & $973 \mathrm{~K}$ & $1023 \mathrm{~K}$ & $1073 \mathrm{~K}$ \\
\hline PBC1 & 0.871 & 0.856 & 0.825 & 0.776 & 0.777 \\
PBC2 & 0.979 & 0.968 & 0.846 & 0.919 & 0.905 \\
PBC3 & $\mathbf{0 . 9 9 3}$ & $\mathbf{0 . 9 8 8}$ & 0.974 & 0.957 & 0.941 \\
D1 & 0.958 & 0.943 & 0.921 & 0.881 & 0.868 \\
D2 & $\mathbf{0 . 9 9 3}$ & 0.984 & 0.974 & 0.952 & 0.932 \\
D3 & 0.937 & 0.963 & 0.974 & $\mathbf{0 . 9 8 0}$ & $\mathbf{0 . 9 6 7}$ \\
D4 & $\mathbf{0 . 9 9 2}$ & $\mathbf{0 . 9 9 1}$ & $\mathbf{0 . 9 8 8}$ & $\mathbf{0 . 9 7 7}$ & $\mathbf{0 . 9 5 7}$ \\
ROM1 & 0.942 & 0.972 & $\mathbf{0 . 9 8 0}$ & $\mathbf{0 . 9 7 9}$ & $\mathbf{0 . 9 6 4}$ \\
ROM2 & 0.648 & 0.758 & 0.813 & 0.798 & 0.780 \\
ROM3 & 0.351 & 0.447 & 0.544 & 0.420 & 0.461 \\
NM1 & 0.981 & $\mathbf{0 . 9 8 9}$ & $\mathbf{0 . 9 8 0}$ & 0.970 & 0.955 \\
NM2 & 0.980 & 0.978 & 0.960 & 0.945 & 0.932 \\
NM3 & 0.957 & 0.949 & 0.920 & 0.899 & 0.89 \\
NM4 & 0.935 & 0.925 & 0.890 & 0.863 & 0.861 \\
\hline
\end{tabular}

the regression lines corresponding to Figure 10. For the second approach, $k$ values were provided by the fitting procedure. The resulting Arrhenius plots for both

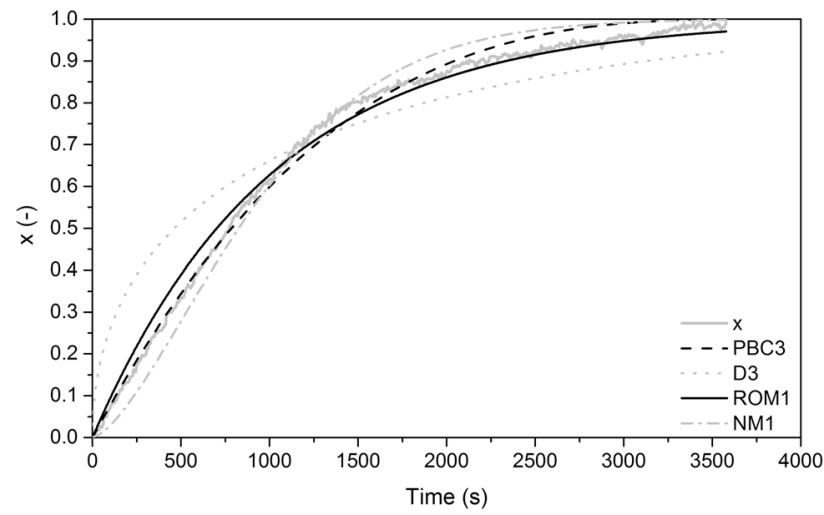

Fig. 11-Model fitting of experimental data for reduction of $\mathrm{FeO}$ to $\mathrm{Fe}$ at $973 \mathrm{~K}$ via fitting rate constant of model to experimental results using selected models from Table III.

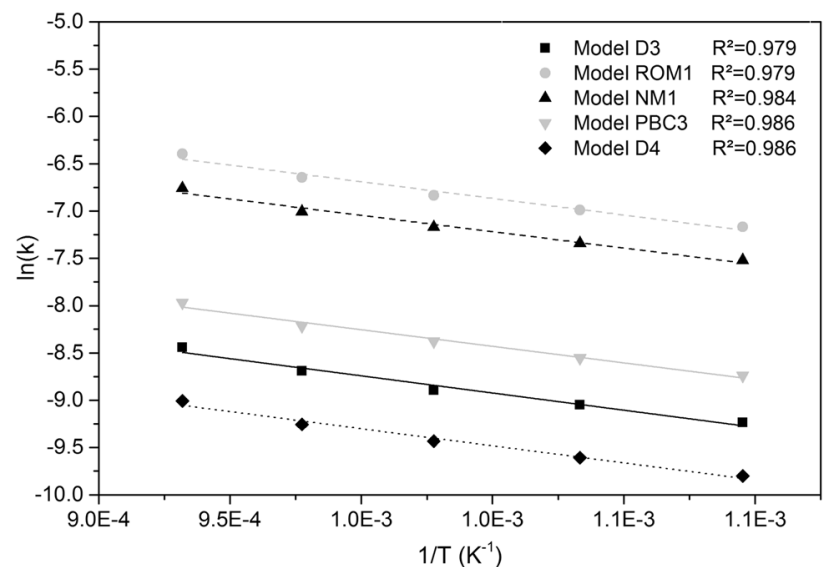

(a)

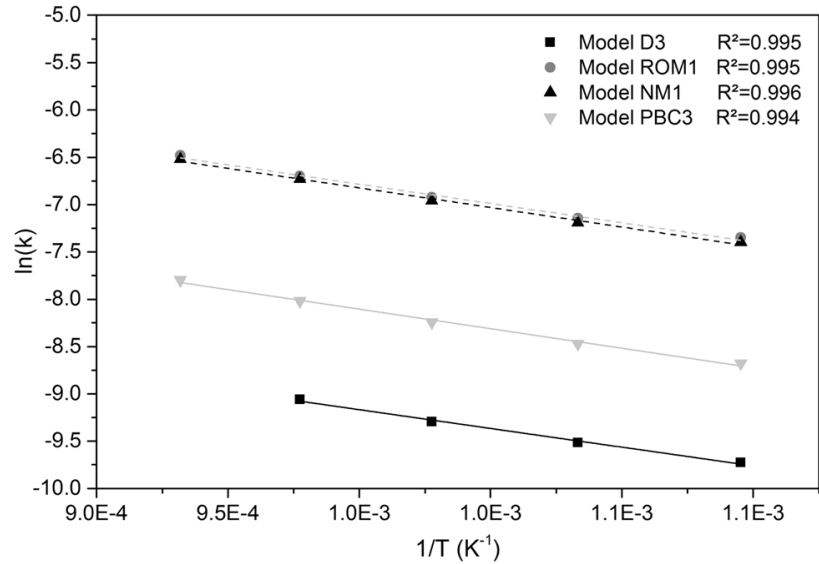

(b)

Fig. 12-Determination of apparent activation energy from different model analyses for the reduction from $\mathrm{FeO}$ to $\mathrm{Fe} ;(a)$ Approach 1; (b) Approach 2. 
Table V. Values of Reaction Rate $k$ and Root Mean Square Deviation RMSD Resulting from Model-Fitting-Approach 2

\begin{tabular}{|c|c|c|c|c|c|c|c|c|c|c|}
\hline \multirow[b]{2}{*}{ Model } & \multicolumn{2}{|c|}{$873 \mathrm{~K}$} & \multicolumn{2}{|c|}{$923 \mathrm{~K}$} & \multicolumn{2}{|c|}{$973 \mathrm{~K}$} & \multicolumn{2}{|c|}{$1,023 \mathrm{~K}$} & \multicolumn{2}{|c|}{$1,073 \mathrm{~K}$} \\
\hline & $k\left(\mathrm{~s}^{-1}\right)$ & RMSD & $k\left(\mathrm{~s}^{-1}\right)$ & RMSD & $k\left(\mathrm{~s}^{-1}\right)$ & RMSD & $k\left(\mathrm{~s}^{-1}\right)$ & RMSD & $k\left(\mathrm{~s}^{-1}\right)$ & RMSD \\
\hline PBC3 & $1.70 \mathrm{E}-4$ & 0.016 & $2.10 \mathrm{E}-4$ & 0.015 & $2.62 \mathrm{E}-4$ & 0.025 & $3.29 \mathrm{E}-4$ & 0.032 & $4.10 \mathrm{E}-4$ & 0.029 \\
\hline D3 & $5.95 \mathrm{E}-5$ & 0.098 & $7.37 E-5$ & 0.099 & $9.18 \mathrm{E}-5$ & 0.099 & $1.16 \mathrm{E}-4$ & 0.097 & $3.66 \mathrm{E}-1$ & 0.108 \\
\hline ROM1 & $6.43 \mathrm{E}-4$ & 0.022 & $7.89 \mathrm{E}-4$ & 0.025 & $9.86 \mathrm{E}-4$ & 0.026 & $1.23 \mathrm{E}-3$ & 0.034 & $1.53 \mathrm{E}-3$ & 0.039 \\
\hline NM1 & $6.13 \mathrm{E}-4$ & 0.044 & $7.53 \mathrm{E}-4$ & 0.040 & $9.49 \mathrm{E}-4$ & 0.040 & $1.19 \mathrm{E}-3$ & 0.040 & $1.47 \mathrm{E}-3$ & 0.022 \\
\hline
\end{tabular}

Table VI. Determined Values of Apparent Activation Energy from Different Model-Fitting Analyses

\begin{tabular}{lcc}
\hline Model No. & $\begin{array}{c}\text { Approach 1 } \\
\mathrm{E}_{\mathrm{a}}\left(\mathrm{kJ} \mathrm{mol}^{-1}\right)\end{array}$ & $\begin{array}{c}\text { Approach 2 } \\
\mathrm{E}_{\mathrm{a}}\left(\mathrm{kJ} \mathrm{mol}^{-1}\right)\end{array}$ \\
\hline PBC3 & 29.13 & 34.33 \\
D3 & 30.19 & 32.98 \\
D4 & 30.14 & - \\
ROM1 & 29.23 & 33.91 \\
NM1 & 28.76 & 34.37 \\
\hline
\end{tabular}

approaches are given in Figure 12. As shown, all regression lines show good coefficients of determination close to 1 .

Table VI shows the resulting values of apparent activation energy, determined by the slope of the regression lines. The apparent activation energy for the reduction of $\mathrm{FeO}$ to $\mathrm{Fe}$ by hydrogen is in the range of 29 to $35 \mathrm{~kJ} \mathrm{~mol}^{-1}$ for every model used. Summarized values of apparent activation energy for the reduction of $\mathrm{FeO}$ to $\mathrm{Fe}$, reported in the literature, are given in Table VII. The values vary in a range between 11 and $104 \mathrm{~kJ} \mathrm{~mol}^{-1}$. Notably, the apparent activation energy depends on many parameters, such as input material, gas composition, type of experiment, etc. ${ }^{[8]}$ Moreover, the occurring rate-limiting step is of importance. For example, Kuila et $a{ }^{[31]}$ defined diffusion as a rate-limiting step, so the apparent activation energy determined is only $11 \mathrm{~kJ}$ $\mathrm{mol}^{-1}$.

For the first two fitting approaches, using integral expression $g(x)$ and the coefficient of determination as well as model-fitting via variation of the rate constant $k$, no general trend can be assumed using only experimental data for the reduction of $\mathrm{FeO}$ to Fe. The use of the $g(x)$ function for model-fitting shows that diffusion also might be a limitation for the reduction process, which is untypical for the reduction of hematite with hydrogen due to the good diffusion behavior of hydrogen compared to carbon monoxide. ${ }^{[36]}$ If dense iron layers formed during reduction do not occur, limitation by diffusion should not be of importance during reduction. To evaluate this, polished micro-sections of partly reduced samples with approximately 40, 60, and $80 \mathrm{pc}$. degree of reduction are shown in Figure 13. It can be seen that the metallic iron formation starts uniformly and is then distributed in the whole particle area, not only on the outer surface of the particle. For that reason, a growing layer of metallic iron around the particle does not occur. This finding confirms that diffusion of the reducing gas to the reaction interface is not significant, especially at the beginning of the metallic iron formation. It seems that only nucleation and chemical reaction may limit the progress of reduction in this case. Further multistep kinetic analysis should confirm this theory.

\section{Multistep Kinetic Analysis of Total Reduction}

from $\mathrm{Fe}_{2} \mathrm{O}_{3}$ to $\mathrm{Fe}$ Using a Parallel Reaction Model Based on the JMA Model

A classic model to describe isothermal gas-solid reactions is the model defined by Johnson-Mehl-Avrami (JMA), ${ }^{[37-40]}$ as shown in Eq. [18],

$$
x=1-e^{-a * t^{n}}
$$

where $x$ represents the conversion, $a$ the nucleation rate constant, $t$ the reduction time and $n$ the kinetic exponent. If $n<1$, the mechanism is considered to be diffusion controlled; if $n$ is close to 1 , the reaction is controlled by reaction kinetics. A value of $n>1.5$ shows that the reaction can be explained by the nucleation process, where $n=1.5$ represents a zero nucleation rate, $n=1.5$ to 2.5 a decreasing nucleation rate, $n=2.5$ a constant nucleation rate and $n>2.5$ an

Table VII. Values of Apparent Activation Energy for the Reduction of FeO to Fe, as Reported in Literature

\begin{tabular}{|c|c|c|c|c|c|}
\hline Reference & Reduction Step & $T$-Range (K) & $\mathrm{Ea}\left(\mathrm{kJ} \mathrm{mol}^{-1}\right)$ & Experimental Method & Type of Experiment \\
\hline Barde et al. $^{[32]}$ & $\mathrm{FeO} \rightarrow \mathrm{Fe}$ & 1073 to 1273 & 30.0 & isothermal $\left(\mathrm{H}_{2}\right)$ & fixed bed \\
\hline Kuila et al. ${ }^{[33]}$ & $\mathrm{FeO} \rightarrow \mathrm{Fe}$ & 973 to 1273 & 55.0 & isothermal $\left(\mathrm{H}_{2}\right)$ & fixed bed \\
\hline Kuila et al..$^{[31]}$ & $\mathrm{FeO} \rightarrow \mathrm{Fe}$ & 973 to 1173 & 11.0 & isothermal $\left(\mathrm{H}_{2}\right)$ & fixed bed \\
\hline Muntenau et al. ${ }^{[27]}$ & $\mathrm{FeO} \rightarrow \mathrm{Fe}$ & 298 to 1073 & 85.7 & non-isothermal $\left(\mathrm{H}_{2}\right)$ & fixed bed \\
\hline Jozwiak et al. ${ }^{[34]}$ & $\mathrm{FeO} \rightarrow \mathrm{Fe}$ & 298 to 1173 & 104.0 & non-isothermal $\left(\mathrm{H}_{2}\right)$ & fixed bed \\
\hline Hou et al..$^{[35]}$ & $\mathrm{FeO} \rightarrow \mathrm{Fe}$ & 863 to 903 & 75.9 & isothermal $\left(\mathrm{H}_{2}-\mathrm{Ar}\right)$ & fixed bed \\
\hline
\end{tabular}



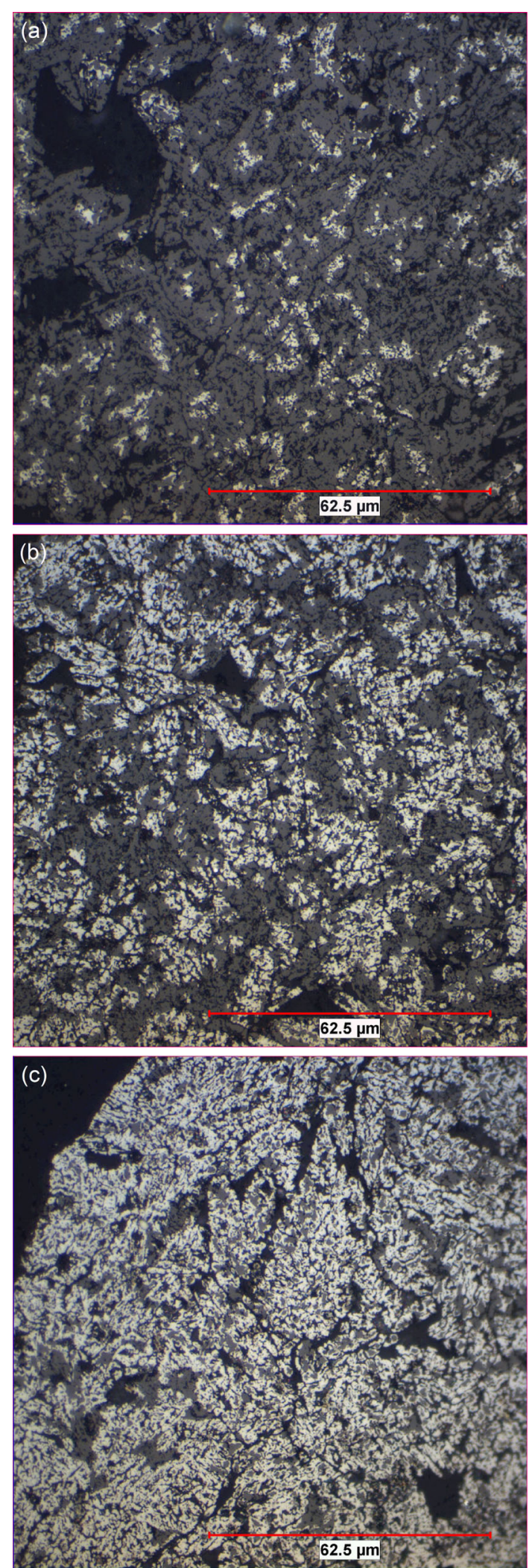

Fig. 13-Polished micro-sections to evaluate progress of reduction: (a) 40 pc. degree of reduction; (b) 60 pc. degree of reduction; (c) 80 pc. degree of reduction; $\mathrm{FeO}$, gray areas; Fe, white areas. increasing nucleation rate. ${ }^{[41]}$ The rate constant $k$ can be determined according to Eq. [19].

$$
k=a^{\frac{1}{n}}
$$

To evaluate more than one process occurring in parallel, a combination of three mechanisms was chosen to reproduce the experimental results as accurately as possible, as shown in Eq. [20], where $x_{0}$ represents the conversion at the beginning of the analysis and $w_{1,2,3}$ the weight factors for three different limiting process steps.

$$
x_{t}=x_{0}+w_{1} x_{1}+w_{2} x_{2}+w_{3} x_{3}
$$

A combination of Eqs. [18] and [20] leads to Eq. [21], considering that $x_{0}$ is zero at the beginning of the analysis.

$$
\begin{aligned}
x_{t}= & w_{1} *\left(1-e^{-a_{1} * t^{n_{1}}}\right)+w_{2} *\left(1-e^{-a_{2} * t_{2}}\right)+w_{3} \\
& *\left(1-e^{-a_{3} * t^{n_{3}}}\right)
\end{aligned}
$$

A similar procedure was carried out by Monazam et al. for the investigation of the oxidation from $\mathrm{Fe}_{3} \mathrm{O}_{4}$ to $\mathrm{Fe}_{2} \mathrm{O}_{3}$, ${ }^{[42]}$ as well as for the reduction of hematite by methane. ${ }^{[43]}$ Fitting Eq. [21] to experimental results was performed using the solver function of Microsoft Excel by a variation of $w_{1,2,3}, a_{1,2,3}$, and $n_{1,2,3}$, to minimize $R M S D$ from the fitting and experimental results. The results of the fitting procedure are exhibited in Figure 14 for different reduction temperatures.

It can be seen that the initial stage of reduction might be controlled by chemical reaction in a temperature range from $873 \mathrm{~K}$ to $973 \mathrm{~K}$, indicated by a kinetic exponent $n_{1}$ close to one. The corresponding weight factor is in the range for a complete reduction of $\mathrm{Fe}_{2} \mathrm{O}_{3}$ to $\mathrm{Fe}_{3} \mathrm{O}_{4}$. At higher reduction temperatures, the kinetic exponent $n_{1}$ decreases below 1 with a simultaneous increase in the weight factor. This means that at higher temperatures, the initial stage of reduction might be controlled by diffusion, whereby it cannot be distinguished between reduction of $\mathrm{Fe}_{2} \mathrm{O}_{3}$ to $\mathrm{Fe}_{3} \mathrm{O}_{4}$ and that of $\mathrm{Fe}_{3} \mathrm{O}_{4}$ to $\mathrm{FeO}$. Accordingly, at higher temperatures, it seems that both reduction steps occur in parallel and are not clearly separated from each other. The modeling results of further reduction show that the process is controlled by a mixture of first-order kinetics and nucleation. At low temperatures, first-order kinetics are dominant. An increasing temperature leads to a decrease in weight factors, with a nearly constant kinetic exponent $n_{2}$ around 1.25. The influence of nucleation becomes more evident with increasing temperatures. At $1073 \mathrm{~K}$ reduction temperature, only nucleation is important. The influence of nucleation can also be seen in the shape of the reduction rate in Figure 7. At the end of the reduction to $\mathrm{FeO}$, the reduction rate is lower compared to the later stages, e.g. 40 pc. degree of reduction. This represents an incubation time for the nucleation of metallic iron. At the end of reduction, nucleation is no longer important, and the reduction rate is only controlled by the chemical reaction. Due to 


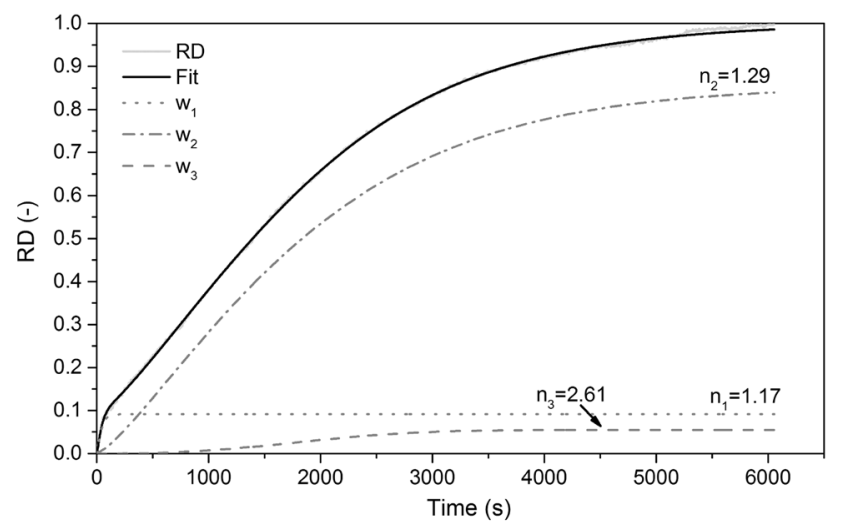

(a)

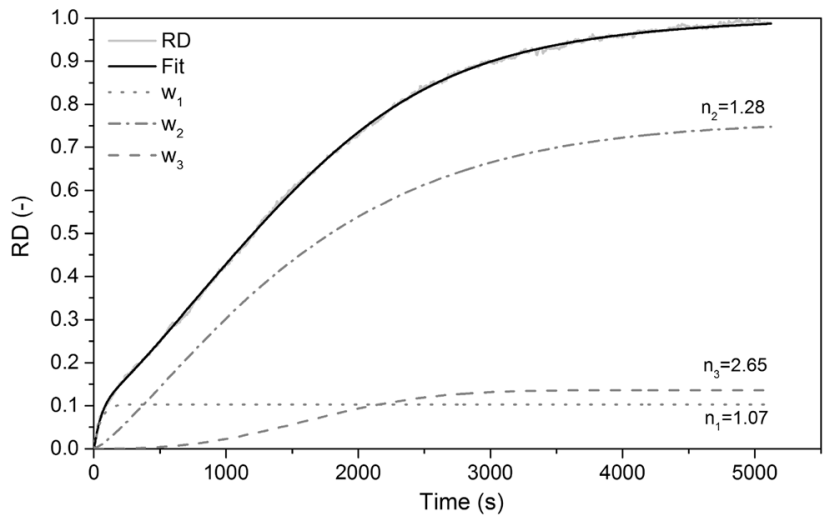

(b)

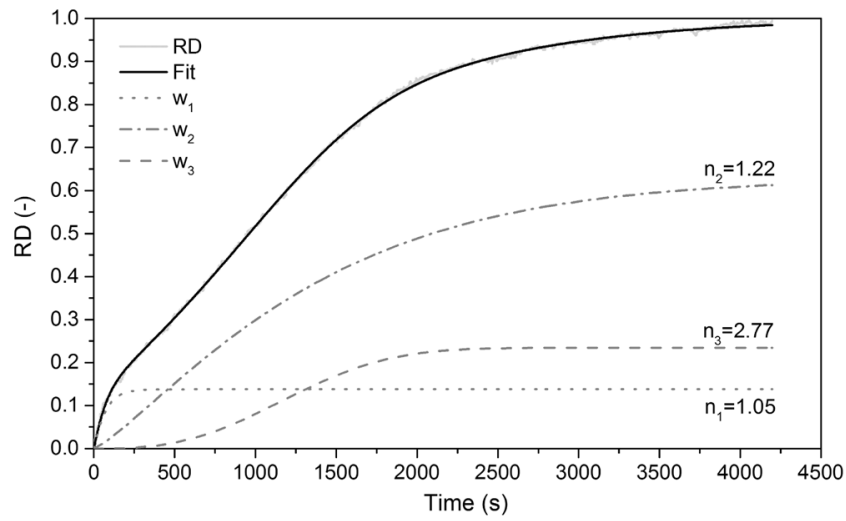

(c)

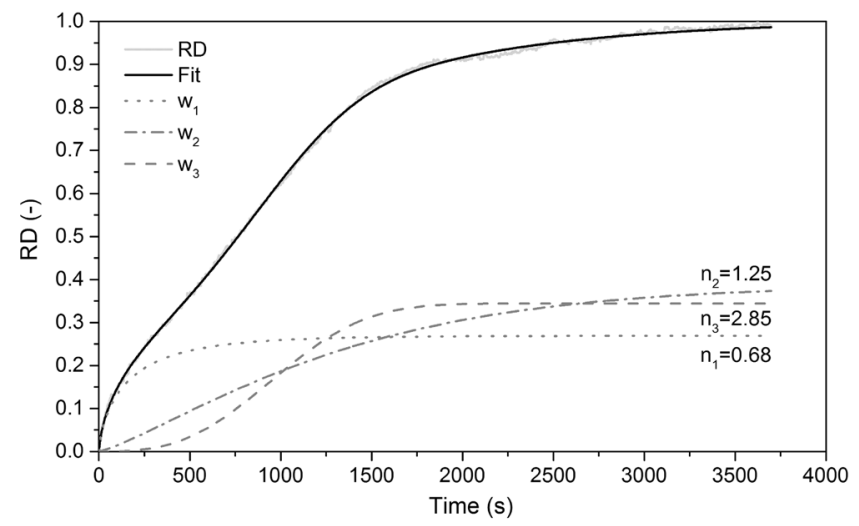

(d)

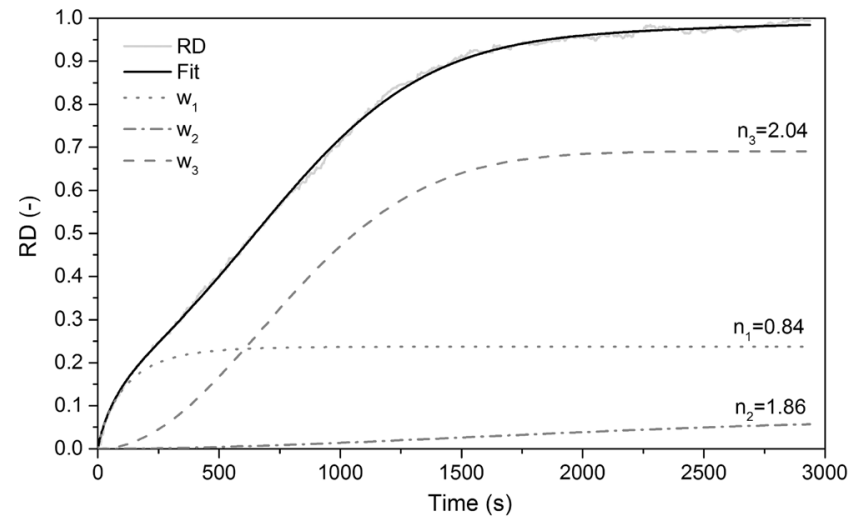

(e)

Fig.14 Kinetical investigation based on JMA model (parallel) at temperatures (a) $873 \mathrm{~K}$, (b) $923 \mathrm{~K},(c) 973 \mathrm{~K},($ d $) 1023 \mathrm{~K}$, (e) $1073 \mathrm{~K}$.

the good diffusion behavior of hydrogen, diffusion does not limit the reduction rate in the final stages of reduction. Table VIII summarizes the resulting values of weight factors, nucleation rate constants and kinetic exponents at different reduction temperatures.

To evaluate which mechanism is acting at a certain degree of reduction, Figure 15 shows the different mechanisms plotted against the experimental degree of reduction: (a) $w_{1}$, (b) $w_{2}$, and (c) $w_{3}$. It is clearly visible that in early stages of reduction, the controlling mechanism changes with increasing temperatures from first-order kinetic to diffusion with increasing weight factor. This results in higher reduction rates at higher temperatures for higher degrees of reduction (20 to 30 pc.). This outcome corresponds to the first peak of the apparent activation energy at a degree of reduction of 12 pc. Furthermore, the weight factor of nucleation increases with increasing temperatures; simultaneously, the weight factor of first-order kinetic decreases. Different changes occur in the reduction rate at certain degrees 
Table VIII. Weight Factors, Nucleation Rate Constants, Kinetic Exponents, and RMSD for Multistep Kinetic Analysis (Parallel) at Different Temperatures

\begin{tabular}{|c|c|c|c|c|c|}
\hline & $873 \mathrm{~K}$ & $923 \mathrm{~K}$ & $973 \mathrm{~K}$ & $1023 \mathrm{~K}$ & $1073 \mathrm{~K}$ \\
\hline$w_{1}$ & 0.0915 & 0.1032 & 0.1379 & 0.2691 & 0.2371 \\
\hline$w_{2}$ & 0.8535 & 0.7607 & 0.6277 & 0.3865 & 0.0722 \\
\hline$w_{3}$ & 0.0549 & 0.1362 & 0.2344 & 0.3443 & 0.6907 \\
\hline$a_{1}$ & 0.0117 & 0.0140 & 0.0109 & 0.0286 & 0.0176 \\
\hline$a_{2}$ & $5.313 \mathrm{E}-05$ & $7.287 \mathrm{E}-05$ & $1.394 \mathrm{E}-04$ & $1.201 \mathrm{E}-04$ & $5.382 \mathrm{E}-07$ \\
\hline$a_{3}$ & $2.064 \mathrm{E}-09$ & $2.065 \mathrm{E}-09$ & $2.065 \mathrm{E}-09$ & $2.065 \mathrm{E}-09$ & $8.614 \mathrm{E}-07$ \\
\hline$n_{1}$ & 1.17 & 1.07 & 1.05 & 0.69 & 0.84 \\
\hline$n_{2}$ & 1.29 & 1.28 & 1.22 & 1.24 & 1.86 \\
\hline$n_{3}$ & 2.61 & 2.65 & 2.76 & 2.86 & 2.04 \\
\hline RMSD & 0.0045 & 0.0048 & 0.0049 & 0.0061 & 0.0070 \\
\hline
\end{tabular}

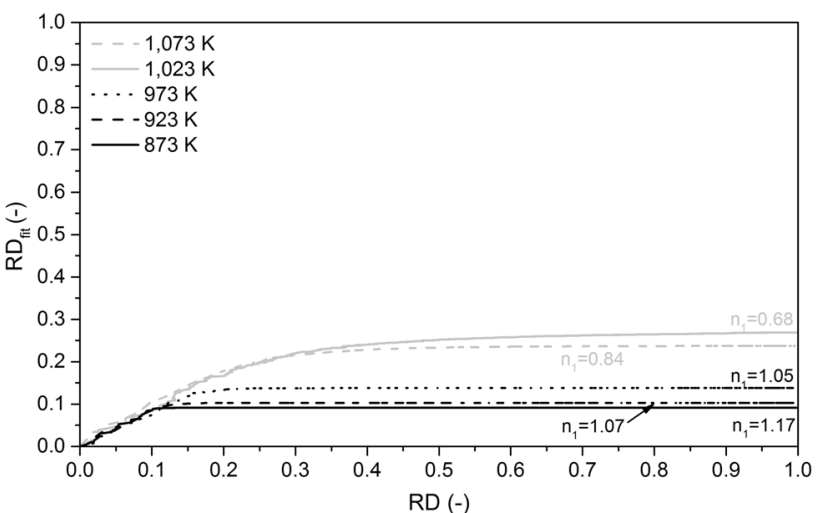

(a)

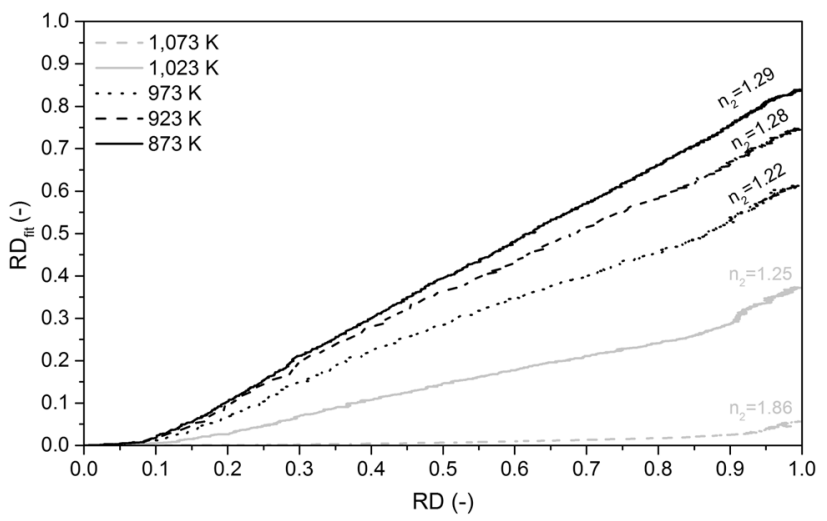

(b)

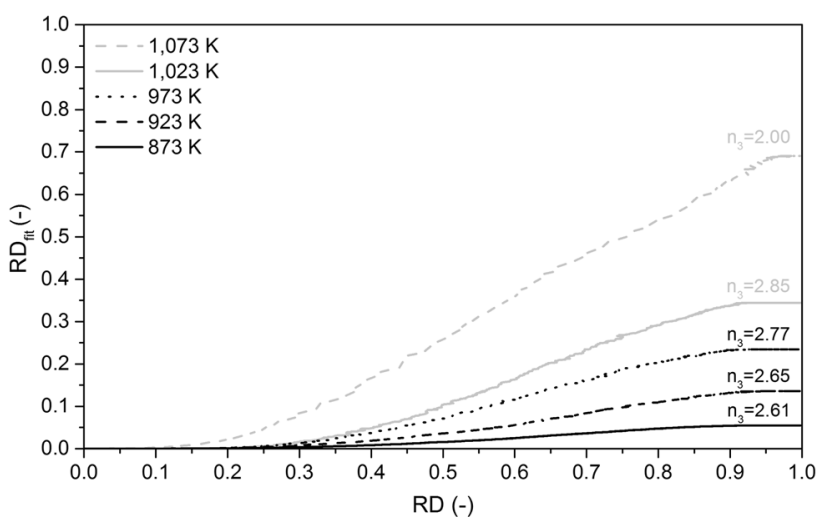

(c)

Fig.15-Plot of different weight factors $(w)$ for different temperatures against degree of reduction: $(a) \mathrm{w}_{1} ;(b) w_{2} ;(c) w_{3}$. of reduction, which matches to the second peak of the apparent activation energy at a degree of reduction of 85 pc. Afterwards, only the first-order reaction is significant, which is why the apparent activation energy decreases. These findings are in agreement with those of the polished micro-sections, displayed in Figure 13. For the reaction mechanisms two and three, representing first-order kinetics and nucleation, activation energies of 19.30 and $33.88 \mathrm{~kJ} \mathrm{~mol}^{-1}$ can be determined, respectively. These values are in good agreement with those shown in Figure 9, where the activation energy increases from 23 to $42 \mathrm{~kJ} \mathrm{~mol}^{-1}$, where both mechanisms are acting in parallel. In the final stage of reduction ( $R D>90 \mathrm{pc}$.), nucleation is not important anymore. The activation energy decreases to the value representing only limitation due to first-order kinetics.

\section{CONCLUSIONS}

A laboratory fluidized bed reactor was used to investigate the reduction kinetics of a fine hematite ore to metallic iron by hydrogen at temperatures from $873 \mathrm{~K}$ to $1073 \mathrm{~K}$. Different approaches for kinetic analysis were used to evaluate the ratelimiting step. Several conclusions can be drawn. First, the influence of kinetic limitation on the reaction rate of reduction reactions decreases drastically with increasing temperatures. At $1073 \mathrm{~K}$, the reduction proceeds near the thermodynamic equilibrium, while at $873 \mathrm{~K}$, the deviation between experimental results and thermodynamic equilibrium is much higher. Second, the reaction kinetics of hematite reduction by hydrogen cannot be described using only one simple gas-solid reaction model. The limiting mechanism varies with temperature and the degree of reduction. Therefore, the apparent activation energy is not constant during the reduction procedure. Third, a two-peak-shaped curve of apparent activation energy against degree of reduction was determined, whereby the apparent activation energy varies from 11 to 55,55 to 23 , and 23 to $42 \mathrm{~kJ} \mathrm{~mol}^{-1}$ for the reduction of $\mathrm{Fe}_{2} \mathrm{O}_{3}$ to $\mathrm{Fe}_{3} \mathrm{O}_{4}, \mathrm{Fe}_{3} \mathrm{O}_{4}$ to $\mathrm{FeO}$, and $\mathrm{FeO}$ to $\mathrm{Fe}$, respectively. Fourth, polished microsections show that at the beginning of metallic iron formation, the iron is formed uniformly and 
distributed in the whole particle, which indicates that diffusion of the reducing gas does not limit the reduction in this case. Lastly, multistep kinetic analysis using the JMA model shows that the initial stage of reduction might be controlled by first-order kinetics and diffusion, depending on the temperature. The reduction of $\mathrm{FeO}$ to $\mathrm{Fe}$ is limited by first-order kinetics and nucleation, whereby the importance of nucleation increases with rising temperatures. Moreover, diffusion is not important in the case of fluidized bed reduction, using hydrogen as a reducing agent during the reduction from $\mathrm{FeO}$ to $\mathrm{Fe}$.

\section{ACKNOWLEDGMENTS}

Open access funding provided by Montanuniversitaet Leoben. The authors would like to acknowledge the financial support from the project $E^{3}-S t e P$ (Enhanced Energy Efficient Steel Production), funded by the Austrian Research Promotion Agency (FFG).

\section{OPEN ACCESS}

This article is distributed under the terms of the Creative Commons Attribution 4.0 International License (http://creativecommons.org/licenses/by/4.0/), which permits unrestricted use, distribution, and reproduction in any medium, provided you give appropriate credit to the original author(s) and the source, provide a link to the Creative Commons license, and indicate if changes were made.

\section{REFERENCES}

1. T.F. Reed, J.C. Agarwal, and E.H. Shipley: J. Met., 1960, vol. 12, pp. 317-20.

2. World Steel Association: Steel Statistical Yearbook. https://www. worldsteel.org, 2017. Accessed 15 Oct 2018.

3. R. Lucena, R. Whipp, and W. Albarran: Stahl Eisen, 2007, vol. 127 , pp. $567-90$.

4. W. Hillisch and J. Zirngast: Steel Times Int., 2001, vol. 3, pp. 20 22 .

5. D. Nuber, H. Eichberger, and B. Rollinger: Stahl Eisen, 2006, vol. 126, pp. 47-51.

6. J.P. Nepper, S. Sneyd, T. Stefan, and J. Weckes: Proceedings of the 6th European Coke and Ironmaking Congress, Düsseldorf, Germany, 2011, pp. 1-7.

7. Lv. Bogdandy and H.-J. Engell: Die Reduktion der Eisenerze: Wissenschaftliche Grundlagen und technische Durchführung, Springer, Berlin, 1967, pp. 18-38.

8. M. Hanel, PhD-thesis, Montanuniversitaet Leoben, 2014.

9. Y.-W. Zhong, Z. Wang, X.-Z. Gong, and Z.-C. Guo: Ironmak Steelmak, 2013, vol. 39, pp. 38-44.
10. B. Zhang, X. Gong, Z. Wang, and Z. Guo: ISIJ Int., 2011, vol. 51, pp. 1403-9.

11. K. Piotrowski, K. Mondal, H. Lorethova, L. Stonawski, T. Szymanski, and T. Wiltowski: Int. J. Hydrogen Energy, 2005, vol. 30, pp. 1543-54.

12. K. Piotrowski, K. Mondal, T. Wiltowski, P. Dydo, and G. Rizeg: Chem. Eng. J., 2007, vol. 131, pp. 73-82.

13. M. Bahgat and M.H. Khedr: Mater. Sci. Eng. B, 2007, vol. 138, pp. 251-58.

14. O.A. Teplov: Russ. Metall. (Engl. Transl.), 2012, vol. 1, pp. 8-21.

15. P. Pourghahramani and E. Forssberg: Thermochim. Acta, 2007, vol. 454 , pp. $69-77$.

16. R.J. Fruehan, Y. Li, L. Brabie, and E.-J. Kim: Scand. J. Metall., 2005 , vol. 34, pp. 205-12.

17. Z. Wei, J. Zhang, B. Qin, Y. Dong, Y. Lu, Y. Li, W. Hao, and Y. Zhang: Powder Technol., 2018, vol. 332, pp. 18-26.

18. A. Pineau, N. Kanari, and I. Gaballah: Thermochim. Acta, 2006, vol. 447 , pp. 89-100.

19. A. Pineau, N. Kanari, and I. Gaballah: Thermochim. Acta, 2007, vol. 456 , pp. $75-88$.

20. VDI-Gesellschaft Verfahrenstechnik und Chemieingenieurwesen: VDI Heat Atlas, 2nd ed., Springer, Berlin, 2010, pp. 131-45.

21. D. Kunii and O. Levenspiel: Fluidization Engineering, 2nd ed., Butterworth-Heinemann, Stoneham, 1991, pp. 68-84.

22. D. Geldart: Gas Fluidization Technology, Wiley, Chichester, 1986, pp. 21-24.

23. A. Haider and O. Levenspiel: Powder Technol., 1989, vol. 58, pp. 63-70.

24. P. Simon: J. Therm. Anal. Calorim., 2004, vol. 76, pp. 123-32.

25. M. Pijolat, L. Favergeon, and M. Soustelle: Thermochim. Acta, 2011, vol. 525, pp. 93-102.

26. H. Chen, Z. Zheng, Z. Chen, and T. Bi: Powder Technol, 2017, vol. 316 , pp. $410-20$.

27. G. Munteanu, L. Ilieva, and D. Andreeva: Thermochim. Acta, 1997, vol. 291, pp. 171-77.

28. M. Shimokawabe, R. Furuichi, and T. Ishii: Thermochim. Acta, 1979, vol. 28, pp. 287-305.

29. A. Ortega: Thermochim. Acta, 1996, vol. 284, pp. 379-87.

30. A. Khawam and D.R. Flanagan: J. Phys. Chem. B, 2006, vol. 110, pp. 17315-28.

31. S.K. Kuila, S. Chaudhuri, R. Chatterjee, and D. Ghosh: Proceedings of the International Conference on Chemical Engineering, Dhaka, Bangladesh, 2014, pp. 80-85.

32. A.A. Barde, J.F. Klausner, and R. Mei: Int. J. Hydrogen Energy, 2016, vol. 41, pp. 10103-19.

33. S.K. Kuila, R. Chatterjee, and D. Ghosh: Int. J. Hydrogen Energy, 2016, vol. 41, pp. 9256-66.

34. W.K. Jozwiak, E. Kaczmarek, T.P. Maniecki, W. Ignaczak, and W. Maniukiewicz: Appl. Catal. A, 2007, vol. 326, pp. 17-27.

35. B. Hou, H. Zhang, H. Li, and Q. Zhu: Chin. J. Chem. Eng., 2012, vol. 20 , pp. 10-17

36. H. Zuo, C. Wang, J. Dong, K. Jiao, and R. Xu: Int. J. Miner. Metall. Mater., 2015, vol. 22, pp. 688-96.

37. W.A. Johnson and R.F. Mehl: Trans. AIME, 1939, vol. 135, pp. $416-58$.

38. M. Avrami: J. Chem. Phys., 1939, vol. 7, pp. 1103-12.

39. M. Avrami: J. Chem. Phys., 1940, vol. 8, pp. 212-24.

40. M. Avrami: J. Chem. Phys., 1941, vol. 9, pp. 177-84.

41. J. Malek: Thermochim. Acta, 1995, vol. 267, pp. 61-73.

42. E.R. Monazam, R.W. Breault, and R. Siriwardane: Ind. Eng. Chem. Res., 2014, vol. 53, pp. 13320-28.

43. E.R. Monazam, R.W. Breault, R. Siriwardane, G. Richards, and S. Carpenter: Chem. Eng. J., 2013, vol. 232, pp. 478-87.

Publisher's Note Springer Nature remains neutral with regard to jurisdictional claims in published maps and institutional affiliations. 